\title{
MACROSCOPY
}

\section{Should the Patent System for New Medicines Be Abolished?}

\section{JA DiMasi ${ }^{1}$ and HG Grabowski ${ }^{2}$}

"It is hard to think of many industries that have contributed as much to human welfare as the pharmaceutical industry." This statement was made not by a pharmaceutical industry chief executive officer but by two antitrust regulators, Roy Levy and Abraham Wickelgren, with the Federal Trade Commission. ${ }^{1}$ There is indeed evidence from the medical and economics literature that new drugs have played a central role in increased longevity, enhanced quality of life, and improved labor-force participation and productivity. Recent studies have attributed as much as half of all welfare gains worldwide during the 20th century to the introduction of new medicines and technologies. ${ }^{2,3}$

Despite these noteworthy accomplishments, the industry has been subjected to hostile criticism and radical policy proposals. One of the major targets of these proposals is the patent system, in which inventors are awarded exclusive rights to develop and commercialize new medicines. A variety of alternative schemes have been offered, but virtually all come down to greater reliance on the government to fund the discovery and development of new drugs. This would be done through either a prize fund for private inventors of new medical technologies or direct government funding of the research through grants and contracts. The advantage claimed for these proposals is that they would lower drug prices and allow greater access to new medicines, because without patents all medicines would be "genericized" at the time of introduction.

\section{Benefits and costs of the patent system} Patents serve many functions in the complex multistaged research and development $(\mathrm{R} \& \mathrm{D})$ process. First, they provide a reward for invention and the incentive to undertake the uncertain and costly $R \& D$ process. ${ }^{4}$ In particular, successes will not be subject to immediate duplication by rival firms that have not yet undertaken this costly investment. Second, patents serve a disclosure function so that knowledge can be publicly disseminated and improvements can be undertaken by subsequent inventors. Beyond these traditional rationales, patents increasingly serve signaling and transactional functions that permit a market to emerge for the exchange of new technologies. This is what we observe in the case of university licensing to new venture start-ups, and the numerous partnership arrangements that now pervade the $\mathrm{R} \& \mathrm{D}$ process for new pharmaceuticals. In particular, patents are a valuable asset that signal a firm's innovative capacity, and also facilitate the movement of capital in the most productive directions.

The classic fundamental criticism levied against patents is that they create market inefficiencies associated with the tendency for patent holders to set price above marginal cost (roughly speaking, production cost). As a result, there will be some consumers who do not purchase the product at the price set by producers but would be willing to purchase it if it were priced at the cost of producing an additional unit. In the case of pharmaceutical and other medical technologies, this leads to an access or underconsumption problem that is best remedied, according to critics, by making all products subject to generic entry upon initial marketing approval, and using nonpatent incentives to stimulate $R \& D$ investment in new medical technologies.

With respect to the access problem, there is little evidence to support the view that insured individuals are underconsuming pharmaceuticals within the current system with patient co-payments and co-insurance serving as the marginal costs to consumers. ${ }^{5}$ To be sure, a considerable number of individuals in the United States have no prescription drug insurance. They face the full retail prices for drugs. Some of the uninsured are wealthy enough or healthy enough that they would purchase the drugs they need nonetheless. However, others will ration their drug usage or go without. The underconsumption produced by patents for this uninsured population, however, can be remedied by taking the much less radical step of insuring the uninsured (at co-payments or co-insurance rates that approximate marginal production costs), rather than replacing patents and their market exclusivities with prize funds or direct government funding and control of drug development. In less developed 
countries, tiered pricing, subsidies, and health-infrastructure improvements can be used to help guarantee access.

A government-run system to develop drugs to the point of regulatory approval would face its own set of serious problems and costs. Nonetheless, activists, scholars, and policymakers have put forth proposals to replace the current framework for financing pharmaceutical $R \& D$ with prize-fund or government-directed systems. Although these proposals contain little operational specificity, we briefly examine their properties and problems.

\section{Government-funded systems: legisla- tive proposals}

Several alternatives to the current patent system for pharmaceuticals have been advanced in recent years, including proposed, but not enacted, legislation in the U.S. Congress. ${ }^{6,7}$ One of the legislative proposals ${ }^{6}$ would take the direct government-funding-and-control approach for the United States by creating a number of public research corporations (perhaps through an expansion of the National Institutes of Health) to conduct not only basic research but also all the development necessary to obtain approval for a drug by the Food and Drug Administration. The other $\operatorname{proposal}^{7}$ takes a prizefund approach, with the total amount of the fund fixed at a certain percentage of gross domestic product (GDP) and payments made on the basis of incremental benefits (with no specified framework for determining these benefits).

The Medical Research and Development Treaty. Perhaps the most broadly encompassing proposal (because it allows for either government-directed or prizefund approaches or both) is the Medical Research and Development Treaty (MRDT) ${ }^{8,9}$ The criticisms we raised with an early version of the MRDT ${ }^{10}$ are still applicable. Since then, its proponents have added the proposal that nations could trade in R\&D credits based on their R\&D expenditures in a Kyoto-style credit system (under the MRDT, each nation would be required to contribute a fixed percentage of its GDP to medical R\&D). Farlow ${ }^{11}$ has found that such a system would probably be unworkable, with many problematic unintended con- sequences, including the prospect that the United States would be a major seller of such credits, with poorer nations consequently paying the United States for their shortfalls in $\mathrm{R} \& \mathrm{D}$ expenditures.

The MRDT suffers from several serious implementation problems. It seems very unlikely that all, or nearly all, countries would agree to a treaty that commits them to contribute a fixed portion of their GDP year after year to fund medical $R \& D$. There would be strong incentives to free-ride, and the treaty has no effective enforcement mechanisms. Since there is no reason for the optimal amount of $R \& D$ to remain fixed as a proportion of GDP, in theory the treaty would also have to be constantly renegotiated or nations would have to cede determination of their financial obligations to a central authority.

Incentive issues for prizes and contracts. Ultimately, the MRDT has to rely on prize-fund mechanisms or a government grants and contracts scheme. There are numerous, and potentially substantial, costs to either system. For example, the possibility that political rent seeking and lobbying will distort research directions is probably strong under either direct government funding or prize schemes. Private for-profit R\&D organizations are also likely to have better information on markets and associated scientific opportunities, and as a result are better able to direct innovative activity to products most valued by consumers.

The temptation for legislators and administrators to undervalue innovations is especially great for prize awards. Government budgetary pressures combined with the appearance of windfall profits to pharmaceutical firms for medical advances would contribute to uncertainties about constraints on the size of prize awards. In the economics literature, the general incentive issue is referred to as the time inconsistency problem. ${ }^{12}$ Because an innovator's R\&D costs will have already been sunk at the time that awards are made, the innovator will have little choice but to comply with an expropriation of much of the value that has been created. This problem can wreak havoc with innovation incentives. Earlystage ventures with high risks would be particularly vulnerable.
In the case of government grants and contracts, adverse selection and a misalignment of incentives also become significant issues, because administrators' motives and agendas are often different from those of researchers or consumers. Adverse selection can occur in terms of which disease categories are supported as well as which organizations are selected to undertake the projects. Inefficiencies also can result from what economists refer to as yardstick competition. ${ }^{12}$ That is, because it is difficult to gauge the effectiveness of R\&D activities, some shirking may occur from reduced efforts or from the pursuit of what is of purely scientific interest. Attempts to deal with this problem by constructing contracts with a high degree of specificity can have their own adverse consequences, because they can stifle innovative approaches to problem solving.

Complementary policy actions. It is important to distinguish policy proposals that eliminate the patent system from several emerging policy measures that complement patents to meet desirable social objectives. In particular, there are circumstances in which the expected market will be too meager to support the costly and risky investments necessary for new agents (e.g., R\&D focused on rare diseases or diseases endemic to poor countries and $\mathrm{R} \& \mathrm{D}$ to combat bioterrorism threats). In such cases, it is appropriate to consider policy measures supplementary to the patent system to encourage R\&D investment activity. ${ }^{13}$

A particular focus of international policy is the development of pharmaceuticals for diseases of poverty such as malaria, leishmaniasis, and Chagas disease. Several new initiatives are underway. One approach involves the development of new drugs and vaccines by public-private partnerships. These virtual-type organizations, funded by groups such as the Gates and Rockefeller foundations, engage in a variety of risk- and reward-sharing arrangements to advance $R \& D$ portfolios dedicated to particular diseases. ${ }^{14}$ It is estimated that worldwide R\&D spending on diseases of poverty concentrated in these pubic-private partnerships could reach $\$ 500$ million by the end of this decade. ${ }^{15}$ 
The concept of an Advanced Market Commitment (AMC), developed by Michael Kremer and colleagues, is another approach to incentivize $\mathrm{R} \& \mathrm{D}$ for diseases of poverty. ${ }^{16,17}$ An AMC is a financial commitment to subsidize the future providers of vaccines or pharmaceuticals that meet targeted technical specifications and demand requirements in developing countries. No funds are expended until an entity successfully meets the specified criteria. In February 2007, five countries (Canada, Italy, Norway, Russia, and the United Kingdom) along with the Gates Foundation committed $\$ 1.5$ billion to launch the first AMC for a pneumococcal vaccine for disease strains prevalent in developing countries. This AMC pilot provides 7 to 10 years of funding with the goal of developing sustainable supply and price conditions for third-world countries. It is estimated that a vaccine meeting the AMC criteria could save the lives of 5.4 million children by $2030 .{ }^{18}$

The U.S. Orphan Drug Act, which uses various "push" and "pull" incentives (tax credits, grants, and market exclusivity) to encourage $\mathrm{R} \& \mathrm{D}$ investment for rare diseases, is another example of a valuable policy change to complement the U.S. patent system. ${ }^{19}$ These voluntary programs for rare and neglected diseases, which use market-derived principles and incentives, are in stark contrast to policies that advocate the elimination of the current patent system, with their expected adverse consequences for pharmaceutical R\&D.

\section{ACKNOWLEDGMENTS}

This project was supported in part by a grant from Pfizer to the Tufts Center for the Study of Drug Development and Duke University. The research, analysis, and writing of the article were conducted independently by the authors.

\section{CONFLICT OF INTEREST}

The Tufts Center for the Study of Drug Development receives a portion of its income from unrestricted grants from industry sources.

\section{๑) 2007 ASCPT}

1. Levy, R. \& Wickelgren, A. Competition policy issues for regulators: a U.S. perspective on pharmaceutical industry cases before the Federal Trade Commission. In Consolidation and Competition in the Pharmaceutical Industry (ed. Kettler, H.) 106-117 (Office of Health Economics, London, UK, 2001).

2. Nordhaus, W. The health of nations: the contribution of improved health to living standards. In Measuring the Gains from Medical Research:An Economic Approach (eds. Murphy, K.M. \& Topel, R.) 9-40 (Chicago University Press, Chicago, 2003).

3. Becker, G., Philipson, T. \& Soares, R. The quantity and quality of life and the evolution of world inequality. Amer. Econ. Rev. 95, 277-291 (2005).

4. DiMasi, J.A., Hansen, R.W. \& Grabowski, H. The price of innovation: new estimates of drug development costs. J. Health Econ. 22, 151-185 (2003).

5. Lakdawalla, D.N. \& Sood, N. Health Insurance as a Two-Part Pricing Contract <http://works. bepress.com/darius_lakdawalla/29> (2006). Accessed 20 August 2007.

6. The Free Market Drug Act of 2004. H.R. 5155, 108th Congress (2004).

7. Medical Innovation Prize Act of 2005. H.R. 417, 109th Congress (2005).

8. Medical Research and Development Treaty (MRDT) <http://www.cptech.org/ workingdrafts/rndtreaty4.pdf $>$ (2005). Accessed 20 August 2007.

9. Love, J. Measures to enhance access to medical technologies, and new methods of stimulating medical R\&D. U.C. Davis Law Rev. 40, 679-715
(2007).

10. DiMasi, J.A. \& Grabowski, H.G. Patents and R\&D Incentives: Comments on the Hubbard and Love Trade Framework for Financing Pharmaceutical R\&D <http://www.who.int/ intellectualproperty/news/en/Submission3. pdf> (2004). Accessed 20 August 2007.

11. Farlow, A. A Global Medical Research and Development Treaty: An Answer to Global Health Needs? (International Policy Network, London, UK, 2007).

12. Tirole, J. The Theory of Industrial Organization. (MIT Press, Cambridge, MA, 1988).

13. Ridley, D.B., Grabowski, H.G. \& Moe, J. Developing drugs for developing countries. Health Aff. 25, 313-324 (2006).

14. Nwaka, S. \& Ridley, R.G. Virtual drug discovery and development for neglected diseases through public-private partnerships. Nat. Rev. Drug Discov. 2, 919-928 (2003).

15. Ridley, R.G. Product development publicprivate partnerships for diseases of poverty: are there more efficient alternatives? are there limitations? Prepared for the Initiative on Public-Private Partnerships Workshop. Combating Diseases Associated with Poverty: Financing Strategies for Product Development and the Potential role of Public-Private Partnerships (London, 15-16 April 2004).

16. Kremer, M. Pharmaceuticals and the developing world. J. Econ. Persp. 16, 67-90 (2002).

17. Berndt, E.R. et al. Advanced Purchase Commitments for a Malaria Vaccine: Estimating Costs and Effectiveness. National Bureau of Economic Research, NBER Working Paper No. 11288 (2005).

18. GAVI Alliance. Five Nations and the Bill and Melinda Gates Foundation Launch Advanced Market Commitments for Vaccines to Combat Deadly Disease in Poor Nations < http://www. vaccineamc.org/media/launch_event_ 01.html> (2007). Accessed 20 August 2007.

19. Grabowski, H. Increasing R\&D incentives for neglected diseases: lessons from the Orphan Drug Act. In International Public Goods, and Transfer of Technology under a Globalized Intellectual Property Regime (eds. Maskus, K.I. \& Reichman, J.H.) 457-480 (Cambridge University Press, Cambridge, UK, 2005). 